\title{
Seasonal changes in number and habitat use of foraging sika deer at the high altitude of Tanzawa Mountains, Japan
}

\author{
Jakub BORKOWSKI* and Kengo FURUBAYASHI
}

\begin{abstract}
Borkowski J. and Furubayashi K. 1998. Seasonal changes in number and habitat use of foraging sika deer at the high altitude of Tanzawa Mountains, Japan. Acta Theriologica 43: 95-106.

Seasonal changes in the population size and habitat use of sika deer Cervus nippon Temminck, 1838 in the high Tanzawa Mountains were studied. Deer exhibited seasonal movements different than those usually observed in the mountains. Because dwarf bamboo, their main winter food, recently occurs only in the high Tanzawa Mts, deer concentrated at the high altitude in late autumn and moved down in winter. after the reduction of bamboo biomass. The most utilized habitat types were forest clearings due to the highest food biomass available. Closed woodland was selected mostly in autumn and winter when deer often fed on fallen leaves and tree bark. Open woodland without bamboo in the understory was highly avoided. Sika deer population in the Tanzawa Mts should be kept at the stable level, which would enable recovery of vegetation. Because recent shrinking in bamboo distribution occurs mostly due to deer grazing pressure in winter, it was suggested to manage habitats in the low mountains in the way to make them attractive to deer also during winter. Supplemental feeding in the low mountains should be also considered.

Division of Agriculture and Agricultural Life Sciences, The University of Tokyo, Yayoi 1-1-1, Bunkyo-ku, 113 Tokyo. Japan (JB): Faculty of Agriculture, Tokyo University of Agriculture and Technology, Fuchu 183, Japan (KF)

Key words: Cervus nippon, seasonal movements, habitat use, Japan
\end{abstract}

\section{Introduction}

Sika deer Cervus nippon Temminck, 1838 are the only cervid in Japan, and are the most numerous large mammal in this country. Deer distribution is discrete, limited mostly to the mountains, which are often separated by large urban areas. In the lower parts of the mountains human activity (industry, agriculture, forestry) is considerable, and therefore sika deer are often forced to utilize the remoter, higher elevations. These habitat conditions bring about the need for careful deer management and conservation. For that purpose, knowledge of the sika deer habitat requirements is very necessary. So far, however, there have been only few studies on this problem (Takatsuki 1983, 1989, Endo 1992, Takatsuki and Nakano 1992, Furubayashi 1996, Shigematsu 1996), and none in the high mountains.

* Present address: Department of Wildlife Management, Forest Research Institute, Bitwy Warszawskiej 3. 00-973 Warsaw, Poland 
The Tanzawa Mountains exhibit most of the above mentioned habitat limitations. They are surrounded by the highly urbanized vicinities of Tokyo, characterized by extremely high human population density, and the lower parts are are under either agriculture or forestry. Furthermore, due to clear-cuts of large forested areas in the 1960s, and subsequent food abundance, the Tanzawa sika deer population increased dramatically (Furubayashi 1996). As a result of deer pressure, distribution of a dwarf bamboo, the main element of the sika deer winter diet (Mitani 1995), has been gradualy shrinking (Furubayashi 1996). At present, its distribution in the Tanzawa Mts is limited to the zone above $1300 \mathrm{~m}$ a.s.l. Thus, knowledge of the relations between deer and their habitat in the high Tanzawa Mts is especially needed.

Among factors which affect patterns of habitat use in cervids, food (Lyon and Jensen 1980, Hanley 1982, Bodurtha et al. 1989) and cover (Mooty et al. 1987, Yeo and Peek 1992) are the most important. Cervids often change their habitat preferences seasonally according to changes in both habitat conditions and requirements of animals (Irwin and Peek 1983, Thirgood 1995). Since the top of Mt. Tanzawa is covered by several habitat types, and sika deer in the Tanzawa Mountains exhibit seasonal changes in their food habits (Mitani 1995), seasonal differences in the habitat use may be expected.

In snowy mountains, the seasonal movements of sika deer are very common (Maruyama 1981, Ito and Takatsuki 1987) and have also been documented in the Tanzawa Mountains (Furubayashi 1996). The usual pattern of such movements is that deer spend the snowless seasons at the higher altitudes, while during winter they move to the lower ones. Because of the seasonal movements, habitats located in the high mountains are not equally important to deer throughout the course of year.

The main aims of this study were: (1) to determine whether and how changes in the dwarf bamboo distribution influenced the seasonal movements of sika deer and (2) to describe the pattern of habitat use by sika deer in the high Tanzawa Mts. It was considered that above information would be neccessary for the future sika deer management and conservation in the Tanzawa Mts.

\section{Study area}

The study was conducted from January 1994 until February 1995 when a high deer mortality occurred and observations stopped, since deer were then encountered only sporadically. The study area (ca 100 ha) was located in the Tanzawa Mountains $\left(35^{\circ} \mathrm{N}, 139^{\circ} \mathrm{E}\right.$ ), central Honsyu, between Mt. Tanzawa (1567 $\mathrm{m}$ a.s.l.) and Mt. Ryugabamba (1500 $\mathrm{m}$ a.s.l.). The study area was rather small, but it was the largest, continuous patch of area in the Tanzawa Mts, where both bamboo species (see below) still occur. Besides, this part of the Tanzawa Mts has been known to carry one of the highest deer densities in the mountains (K. Furubayashi, unpubl.). Moreover, six radio-collared, non-migratory individuals did not roam out of the study area (Borkowski 1996), thus its size seems to be sufficient. On the ridge there is a tourist trail dividing the study area into two parts: western and eastern.

There were five main habitat types, varying in cover and food condition, recognized in the study area. The classification was based both on aerial photos and ground inspections. Clearings (C) 
occurred in small patches $(0.2-1.2 \mathrm{ha})$, had no overstory, and the ground vegetation level was dominated by a dwarf bamboo Sasa hayatae. The clearings occurred predominately near the ridge. Closed woodland $(\mathrm{Cw})$ covering mostly the eastern part of the study area had dense overstory, created by numerous species of trees, with dominating Weigela dekora, Rhododendron sp., Enkianthus campanulatus, Elaegnus umbellata, Acer japonicum and Tilia japonica. Most of the trees were lower than $10 \mathrm{~m}$. The ground vegetation was dominated by Sasa hayatae. About $30 \%$ of the closed woodland in the western part of the study area and about $20 \%$ of the closed woodland in the eastern area had its understory dominated by another dwarf bamboo species, Pseudosasa purpurascens. This bamboo occured only in the closed woodland. Open woodland $(\mathrm{Ow})$ had an overstory composed mostly by Fagus crenata trees, about $20 \mathrm{~m}$ in height, with numerous gaps in the canopy due to the natural mortality of trees. The understory was either very scarce or absent and the ground vegetation was dominated by Sasa hayatae. This kind of habitat predominately covered the eastern slopes of the study area. In the northern part, there was a habitat (Ow1) similar in over- and understory to Ow, but the ground vegetation level was mostly composed by unpalatable to deer plant species. Erosion sites (E) were especially common on the slopes with western exposures, which were generally steeper than the eastern ones. This habitat had no overstory and beside some grasses in very low biomass, there was no vegetation at the ground level. Since erosion sites were not visible from the trail, no direct deer observation were possible in this habitat. Because of the high deer browsing pressure no successful forest regeneration occured in the study area.

There are no natural predators of sika deer. Hunting (antlered deer only) in the Tanzawa Mountains is allowed in the zone below $800 \mathrm{~m}$ in altitude. The number of tourists visiting the study area depends on the season, and is quite high (up to 200-300 people per day) on weekends and holidays from late September till June and lower in July and August.

\section{Material and methods}

\section{Food biomass}

Vegetation was sampled in three habitat types (clearings, open woodland and closed woodland), four times: in September '94, December '94, April '95 and June '95, which corresponds to the end of each season: summer (July-September), autumn (October-December), winter (January-April) and spring (May-June), respectively. There were from 78 to $87,50 \times 50 \mathrm{~cm}$, quadrats set around the study area in every season. The quadrats were more or less evenly distributed among the habitats. All plants from each quadrat were hand-clipped and divided into four groups: Sasa hayatae, Pseudosasa purpurascens, grasses and forbs. Since the undergrowth was extremely scarce, the browse biomass was negligible, and therefore it was not measured. The plants (in the case of both dwarf bamboo species only leaves and buds) were oven-dried $\left(48\right.$ hours at $\left.80^{\circ} \mathrm{C}\right)$ and subsequently the biomass was measured and recalculated for $\mathrm{g} / \mathrm{m}^{2}$.

\section{Direct observations}

The tourist trail between Mt. Tanzawa and Mt. Ryugabamba (about $1.5 \mathrm{~km}$ ) was walked four times a day: soon after sunrise, before noon, in the afternoon and a short time before sunset, several (8-12) days a month, and not longer than three days per one bout. Exact times depended on day length and two consecutive walks were separated by at least two hours, usually being three or more. When walking the trail, the following information about encountered deer were recorded: time, habitat type, deer number and activity. The data were collected for each period of a day when walking only one direction.

Assuming that changes in the number of deer present in high mountains are influenced by deer seasonal movements, in order to determine the pattern of seasonal movements in Tanzawa, changes in the monthly number of deer present in the study area were recorded. Deer were counted along the tourist trail during each daily observation period. Because line-transect methods of animal population estimation tend to underestimate the real number (Lancia et al. 1994), for a given month, the 
maximum number of deer encountered during a single observation period (usually in the morning) was selected and considered as the population estimate for that month. The estimate obtained in this way was probably the closest to the real one.

Since it is easier to observe animals in the open habitats compared to concealing ones, the habitat use studied on the basis of direct observations may be biased towards clearings. To avoid this, the following procedure has been applied: in order to assess habitats available, the visibility distance from every part of the trail was estimated, and obtained in this way a "visibility zone" was drawn on a 1:5000 map. After that it was overlapped on a habitat map, delineated on tracing paper and then different habitats were cut out, their weights were measured and the respective percent estimated. On the basis of these percent expected deer distributions were calculated.

Differences in food biomass were tested using analysis of variance (ANOVA). When necessary, in order to meet the assumptions of normality and homogeneity of variance, logarithm transformation was applied. Habitat use was analyzed using $G$-test.

\section{Results}

\section{Food biomass}

The biomass of Pseudosasa purpurascens varied between seasons $(F=4.2$, $\mathrm{df}=3,46, p<0.05)$, being the highest in summer and the lowest, close to zero, in winter (Table 1). Sasa hayatae exhibited similar seasonal changes $(F=77.3$,

Table 1. Biomass of sika deer food $\left(\mathrm{g} / \mathrm{m}^{2}\right)$ on the top of Mt. Tanzawa in different seasons and yearly. Habitats: $\mathrm{Cw}$ - closed woodland, $\mathrm{Ow}$ - open woodland, $\mathrm{C}$ - clearings.

\begin{tabular}{|c|c|c|c|c|c|}
\hline Season & Food category & $\mathrm{Cw}$ & Ow & $\mathrm{C}$ & Mean \\
\hline \multirow[t]{4}{*}{ Spring } & P. purpurascens & 58.4 & - & - & - \\
\hline & S. hayatae & 53.4 & 83.7 & 106.8 & 74.1 \\
\hline & other grasses & 2.6 & 10.2 & 13.7 & 8.4 \\
\hline & forbs & 2.0 & 7.2 & 2.8 & 3.9 \\
\hline \multirow[t]{4}{*}{ Summer } & P. purpurascens & 102.8 & - & - & - \\
\hline & S. hayatae & 62.6 & 101.9 & 195.5 & 119.1 \\
\hline & other grasses & 2.6 & 12.9 & 19.6 & 11.1 \\
\hline & forbs & 1.7 & 3.9 & 2.2 & 2.5 \\
\hline \multirow[t]{4}{*}{ Autumn } & P. purpurascens & 58.9 & - & - & - \\
\hline & S. hayatae & 41.4 & 53.6 & 103.4 & 57.7 \\
\hline & other grasses & 0.1 & 0.7 & 4.9 & 1.7 \\
\hline & forbs & - & - & - & - \\
\hline \multirow[t]{4}{*}{ Winter } & P. purpurascens & 3.4 & - & - & - \\
\hline & S. hayatae & 6.6 & 8.2 & 13.4 & 9.2 \\
\hline & other grasses & - & - & - & - \\
\hline & forbs & - & - & - & - \\
\hline \multirow[t]{4}{*}{ Mean } & P. purpurascens & 64.2 & - & & - \\
\hline & S. hayatae & 41.0 & 61.0 & 104.7 & - \\
\hline & other grasses & 1.7 & 7.9 & 12.7 & - \\
\hline & forbs & 1.8 & 5.5 & 2.5 & - \\
\hline
\end{tabular}


$\mathrm{df}=3,273, p<0.001)$. The spring and summer biomass of other grasses were similar $(F=2.8, \mathrm{df}=1,174, p>0.05)$, while their autumn biomass exhibited significant reduction $(F=27.9$, $\mathrm{df}=1,174, p<0.001)$. Forbs biomass in spring was higher than that in summer $(F=4.1, \mathrm{df}=1,173, p<0.05)$.

The biomass of Sasa hayatae was higher in the clearings than both in the open woodland $(F=23.4, \mathrm{df}=168,1, p<0.001)$ and in the closed woodland $(F=50.2$, $\mathrm{df}=1,185, p<0.001)$. The biomass of $S$. hayatae in the closed woodland was lower than in the open woodland $(F=8.8, \mathrm{df}=1,150, p<0.01)$. When comparing the biomass of $S$. hayatae in the closed woodland with the biomass of Pseudosasa purpurascens, except for summer, both values did not differ significantly (spring: $F=0.2, \mathrm{df}=1,82, p>0.05$; autumn: $F=3.0, \mathrm{df}=1,74, p>0.05$; winter: $F=2.8$, $\mathrm{df}=1,62, p>0.05)$; in summer, biomass of $P$. purpurascens was higher than that of $S$. hayatae in closed woodland $(F=16.6, \mathrm{df}=1,78, p<0.01)$. Biomass of other grasses also varied among habitats $(F=20.8, \mathrm{df}=2,261, p<0.001)$ and again the maximum biomass was recorded in the clearings and the minimum in the closed woodland. Forbs, contrary to the other food items, were more abundant in the open woodland than in both clearings $(F=4.8, \mathrm{df}=1,107, p<0.05)$ and closed woodland $(F=16.5, \mathrm{df}=119, p<0.001)$. Forb biomass in the closed woodland did not differ from that in the clearings $(F=2.9 \mathrm{df}=1,119, p>0.05)$.

Assuming that the coefficient of variation of the food biomass, may be an indicator of the food distribution, it is possible to speculate that the patterns of food distribution varied between habitats (Table 2). Since the biomass of studied plants in the closed woodland was lowest, the fact that the coefficient of variation within the closed woodland in most cases was the greatest seems to be of little interest. More important is the comparison between open woodland and clearings. The distribution of Sasa hayatae in autumn was significantly less uniform in the

Table 2. Coefficients of variation (\%) food biomass on the top of Mt. Tanzawa. $\mathrm{Cw}$ - closed woodland, $\mathrm{Ow}$ - open woodland, $\mathrm{C}$ - clearings. Asterisks indicate the significant differences in coefficients of variation between forest and openings $\left(* p<0.05,{ }^{* *} p<0.01,{ }^{* * *} p<0.001\right)$.

\begin{tabular}{llcccc}
\hline Food category & Habitat & Spring & Summer & Autumn & Winter \\
\hline Sasa hayatae & Cw & 57 & 60 & 95 & 256 \\
& Ow & 35 & 33 & $156^{*}$ & 150 \\
\multirow{5}{*}{ Other grasses } & $\mathrm{C}$ & 36 & 37 & 106 & 108 \\
& $\mathrm{Cw}$ & 168 & 167 & 406 & - \\
& Ow & $118^{* *}$ & $182^{* * *}$ & $247^{* *}$ & - \\
Forbs & $\mathrm{C}$ & 73 & 94 & 150 & - \\
& $\mathrm{Cw}$ & 181 & 110 & - & - \\
& Ow & 109 & 136 & - & - \\
& $\mathrm{C}$ & 142 & 139 & - & - \\
\hline
\end{tabular}


open woodland than in the clearings, and the distribution of other grasses exhibited the same trend in all the seasons in which they were recorded.

\section{Deer number}

The number of sika deer seen on the top of Mt. Tanzawa changed throughout the study. Deer number increased to up to 80 individuals from January to February 1994 and then decreased, being relatively stable from March to November 1994 at a level of about 20 to 40 individuals. It began to increase again in December 1994 and reached the peak (120 individuals) in January 1995, when it started to decrease, and in February 70 individuals were seen. High deer number in 1995 have caused quick deterioration of food resources, which together with the deep snow in March caused mass mortality. Since the undergrowth was scarce, seasonal variations in visibility condition were minor, and therefore, they did influence changes in number of deer seen througout the study.
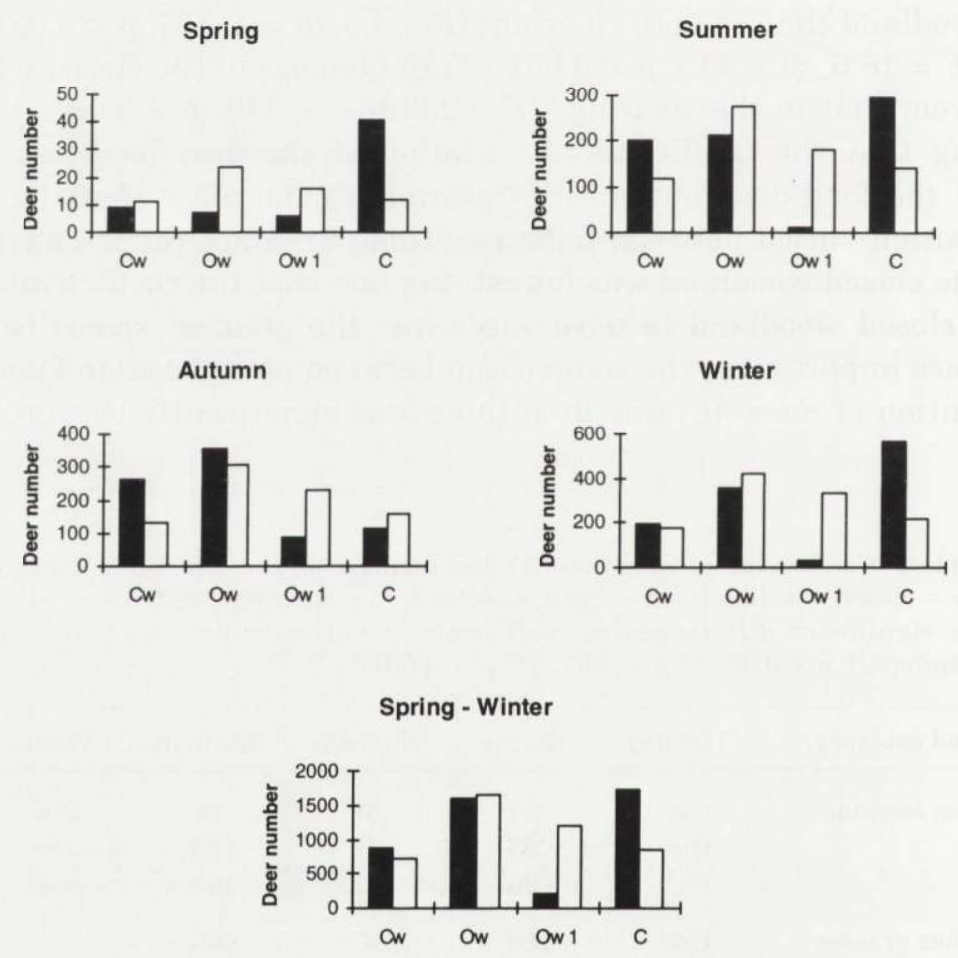

Fig. 1. Habitat use by sika deer on the top of Mt. Tanzawa. Black bars - observed distribution, white bars - expected distribution (on the basis of respective proportion of habitats within "visibility zone" in the study area; see Material and methods for the explanation of "visibility zone"). Cw - closed woodland, Ow - open woodland, Ow1 - open woodland with the understory dominated by unpalatable plant species, $\mathrm{C}-$ clearings. In every case $p<0.001$. 


\section{Habitat use}

The habitat composition within the visibility zone in the study area, between June and October (tree leaves present) and November and May (trees without leaves) - given in parenthesis, were: closed woodland - $16.7 \%(15.7 \%)$, open woodland with bamboo in understory $-38.3 \%$ (36.5\%), open woodland with understory dominated by unpalatable plant species $-25.4 \%$ (28.9\%), and clearings - $19.6 \%(18.9 \%)$. Analysis of habitat use were based on observations of 6007

\section{Closed woodland}

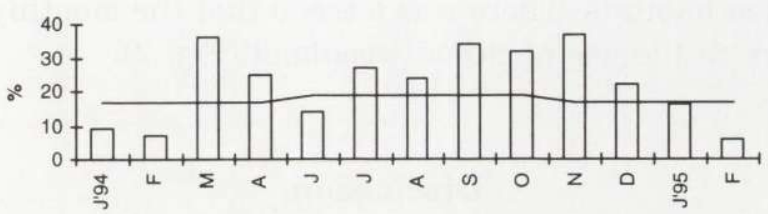

Open woodland

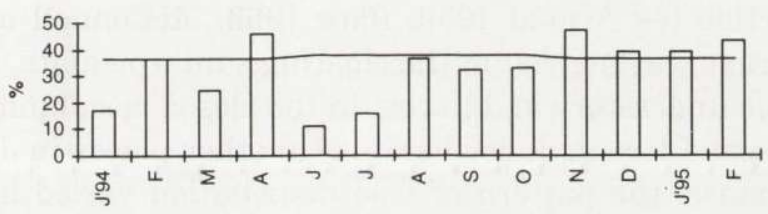

Ow1

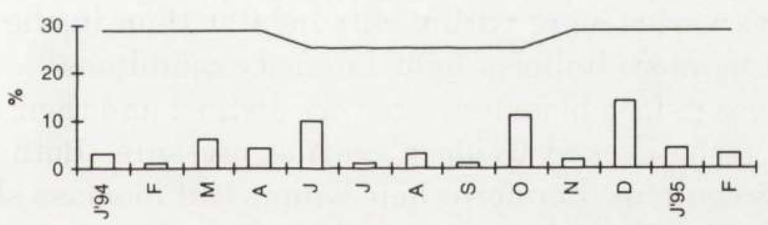

Clearings

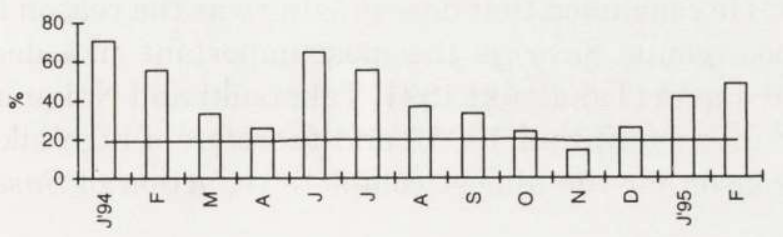

Fig. 2. Changes in the use of each habitat type by sika deer on the top of Mt. Tanzawa. Horizontal line indicates habitat availability within "visibility zone" in the study area (see Material and methods for the explanation of "visibility zone"). Ow1 - open woodland with the understory dominated by unpalatable plant species. For every month $p<0.001$. 
individuals. Sika deer did not use their habitats in proportion to availability $(G=1998.3, \mathrm{df}=3, p<0.001)$. They showed clear preference for the clearings, and avoided old forest with ground vegetation dominated by unpalatable plant species (Fig. 1). Habitat use varied seasonally, and in every season it was disproportional to the occurrence of habitats within the study area (spring: $G=67.2, \mathrm{df}=3, p<0.001$; summer: $G=473.0, \mathrm{df}=3, p<0.001$; autumn: $G=840.6$, $\mathrm{df}=3, p<0.001$; winter: $G=229.6, \mathrm{df}=3, p<0.001$ ). In every season, deer avoided open woodland with ground vegetation dominated by unpalatable plant species, and except for autumn they selected clearings. In autumn, deer increased their use of forested habitats. There was a trend that the monthly use of clearings was an alternative to the use of closed woodland (Fig. 2).

\section{Discussion}

Food biomass on the top of Mt. Tanzawa followed the well known ecological relationship between the level of openness of the forest canopy and ground vegetation production (eg Arnold 1950, Pace 1958, McConnell and Smith 1971). The biomass of forage was highest in the clearings, intermediate in open woodland with bamboo in the understory and lowest in the closed woodland. A similar trend has also been reported for sika deer habitats in other places in Japan (Takatsuki 1990). Beside biomass, the pattern of food distribution varied between habitats. Due to the low biomass of food in the closed woodland, differences in forage distribution between the open woodland and clearings are more important. Since the forest canopy consists of many gaps, it is not surprising that the ground vegetation biomass varies more within this habitat than in the clearings, which are characterized by more uniform light intensity conditions.

Seasonal changes in food biomass were very distinct and their intensity in great measure seemed to be evoked by deer grazing pressure. Both species of dwarf bamboo are evergreen and therefore their winter leaf biomass should not exhibit such reduction, unless it was heavily used by deer. Ushizawa (1996) compared leaf biomass of the Sasa hayatae on the top of Mt. Tanzawa inside a deer proof enclosure with that outside, and found the winter leaf biomass inside the fence was much higher. He concluded that deer grazing was the reason for the difference. The dwarf bamboo (genus $S a s a$ ) is the most important sika deer winter food in many localities in Japan (Takatsuki 1991, Takatsuki and Nakano 1992), including the Tanzawa Mountains (Mitani 1995), and therefore a high sika deer density is likely to be the reason for the almost complete reduction of Sasa leaf biomass in winter.

Sika deer in this study exhibited had different seasonal movements from those usually observed in mountain areas. Deer concentrated in the high mountains in late autumn and moved to lower levels in mid-winter. When the biomass of other grasses decreases and becomes dry in late summer/early autumn, deer in the 
Tanzawa Mountains increasingly feed on dwarf bamboo (Mitani 1995) and its contribution to the deer diet reaches a level of $80 \%$ January to March. When the availability of dwarf bamboo decreases, deer move down in mid-winter and feed mostly on fallen leaves. Makino (1996) found a high contribution of fallen leaves to deer diet in the lower Tanzawa Mts, even in March and April. The present distribution of the dwarf bamboo, limited mostly to the high mountains, apparently influences the pattern of seasonal sika deer movements.

Since most of deer were observed while feeding (Borkowski 1996), their pattern of habitat use mostly reflects the need for forage. The open woodland with understory dominated by unpalatable plant species was strongly avoided. In the past, the understory of this habitat was composed of Pseudosasa purpurascens (K. Furubayashi, pers. comm.), and it was heavily modified by deer grazing pressure. As a result, the value of habitat to deer apparently became extremely low. Therefore, the recently observed process of reduction in distribution of $P$. purpurascens in the Tanzawa Mts means reduction in habitat value.

High use of clearings by sika deer in this study is in accordance with a general trend exhibited by cervids. Preferences towards either natural clearings or clear-cuts with their high forage biomass are well documented (eg Peek et al. 1976, Lyon and Yensen 1980, Collins and Urness 1983, Catt and Staines 1987, Welch et al. 1990). Besides food, the small size of the Tanzawa clearings also influenced their intense usage. Cervids hesitate to use large open areas, especially parts located far from cover (Short et al. 1977, Singer 1979, Lyon and Yensen 1980, Thirgood and Staines 1989), which has also been reported for sika deer (Takatsuki 1989). Use of clearings in spring and summer may also be influenced by less insect harassment caused by stronger breezes, as has been reported for elk (Collins et al. 1978).

The use of the open woodland with dwarf bamboo in the understory was generally proportional to availability. Use might, however, be concentrated in some parts of this habitat, especially those under the canopy gaps. Food distribution within the open woodland was highly clumped. In spring and summer grasses other than bamboo are very important food for sika deer in the Tanzawa Mountains (Mitani 1995). Although grass availability on the top of Mt. Tanzawa was highest in the clearings, the dense "carpet" of bamboo growing in this habitat makes feeding on them difficult. Thus, deer may prefer grazing under the forest canopy gaps where grasses biomass is also high, while bamboo density is less, which makes other grasses easier to graze. Welch et al. (1990) pointed out that red deer used certain places within several habitats much more intensely than others, and the usage was proportional to the percentage of vascular plant cover. The value of open woodland as deer habitat would presumably be higher if the understory consisted also of browse, which could be important food in winter during the presence of snow cover.

Although closed woodland provides sika deer with cover, food was an important factor influencing its use. In late winter many deer used closed woodland in order 
to feed on tree bark. Debarking was very common, especially in winter 1994 (Borkowski et al., in prep.), when bamboo was either reduced by deer grazing or covered by snow. Autumn was another season when increased usage of closed woodland was associated with feeding. In autumn, sika deer in the Tanzawa Mts often consume fallen leaves. Mitani (1995) found that 15-30\% of the diet between October and December was composed of fallen leaves. In this study, fallen leaves might be even more important, since other grasses which were significant deer autumn food in Mitani's study were not as abundant in our study area. The presence of both Pseudosasa purpurascens and browse would make closed woodland a habitat of even greater importance to sika deer.

\section{Conclusions}

The present shrinking of the distribution of bamboo occurs mostly due to winter grazing, in great measure because deer concentrate in the high mountains in early winter. Thus, proper habitat management at the lower elevations should help to keep migratory deer in the low mountains during winter. First, some clearings should be created in order to provide the deer with sufficient forage. This would also make deer hunting and counting easier. The size of open areas does not have to be large, since smaller ones are preferred by deer because of easier access to cover. To some extent, the open woodland may serve as a foraging area and this fact should be considered in cases when creating clearings is difficult.

Because of its high biomass, dwarf bamboo will probably be an attractive winter food for deer inhabiting lower altitudes, even after any habitat improvements. Therefore winter supplemental feeding in lower mountains should be considered.

Seasonal deer movements should be studied in detail. It is important to know from which parts of the mountains the deer come concentrating on the top before winter. Reducing their number in late autumn before they move up would help the bamboo.

The mass mortality of deer similar to that recorded during this study is likely to happen in the future. Because of the spatial isolation of the Tanzawa Mts, repeated low deer densities might be dangerous for the population genetic diversity due to, for instance, demographic bottleneck (Meffe and Carroll 1994), and therefore the population should be kept at the stable level. This level, however, should be low enough to reduce the pressure of deer on the vegetation. Thus, after the population will increase, careful deer control is recomended.

Acknowledgments: We are grateful to Prof K. Furuta, Prof S. Takatsuki and T. Kagaya of Tokyo University as well as to M. Yamane of Kanagawa Forest Research Institute for their advice. We also express our thanks to the members of Tanzawa Nature Conservation Association for their logistic support and field assistance. 


\section{References}

Arnold J. E. 1950. Changes in ponderosa pine bunchgrass ranges in northern Oregon resulting from pine regeneration and grazing. Journal of Forestry 48: 118-126.

Bodurtha T. S., Peek J. M. and Lauer J. L. 1989. Mule deer habitat use related to succession in a bunchgrass community. Journal of Wildlife Management 53: 314-319.

Borkowski J. 1996. The ecology of sika deer in relation to their habitat at the high altitude of Tanzawa Mtn. Ph D thesis, University of Tokyo, Tokyo: 1-105.

Catt D. C. and Staines B. W. 1987. Home range use and habitat selection by Red deer in a Sitka spruce plantation as determined by radio-tracking. Journal of Zoology, London 211: 681-693.

Collins W. B. and Urness P. J. 1983. Feeding behaviour and habitat selection of mule deer and elk on northen Utah summer range. Journal of Wildlife Management 47: 646-663.

Collins W. B., Urness P. J. and Austin D. D. 1978. Elk diets and activities on different lodgepole pine habitat segments. Journal of Wildlife Management 42: 799-810.

Endo A. 1992. Spatial distribution of rutting male relevant to female home range in the sika deer (Cervus nippon) in the Nozaki Island. M Sc thesis, Kyusyu University, Fukuoka: 1-49.

Furubayashi K. 1996. [The studies on protection of sika deer in the Tanzawa Mountains]. Ph D thesis, University of Kyoto, Kyoto: 1-186. [In Japanese]

Hanley T. A. 1982. Cervid activity patterns in relation to foraging constraints: western Washington. Northwest Science 56(3): 208-217.

Ito T. and Takatsuki S. 1987. [The distribution and seasonal movements of sika deer in the Mt. Goyo area, Iwate Prefecture]. Bulletin of Yamagata University, Natural Science 11(4): 411-430. [In Japanese with English summary]

Irwin L. L. and Peek J. M. 1983. Elk habitat use relative to forest succession in Idaho. Journal of Wildlife Management 47: 664-672.

Lancia R. A., Nichols J. D. and Pollock K. H. 1994. Estimating the number of animals in wildlife populations. [In: Reseqarch and management techniques for wildlife and habitats. T. A. Bookhout, ed]. Fifth ed. The Wildlife Society, Bethesda, Md.: 215-253.

Lyon L. J. and Jensen C. E. 1980. Management implications of elk and deer use of clear-cuts in Montana. Journal of Wildlife Management 44: 352-362.

Makino S. 1996. [Food habits and habitat selection of tame sika deer Cervus nippon in upper zone in the Tanzawa Mt]. Graduate thesis. Tokyo University of Agriculture and Technology, Tokyo: 1-77. [In Japanese].

Maruyama N. 1981. [A study of the seasonal movements and aggregation patterns of sika deer]. Bulletin of Faculty of Agriculture of Tokyo University of Agriculture and Technology 23: 1-85. [In Japanese with English summary]

McConell B. R. and Smith J. G. 1971. Response of understory vegetation to ponderosa pine thinning in eastern Washington. Journal of Range Management 23: 203-212.

Meffe G. K. and Carroll C. R. 1994. Principles of conservation biology. Sinauer Associates, Inc., Sunderland, U.S.A.: 1-600.

Mitani N. 1995. [Foraging behavior of tame Sika deer on Mt. Tonotake, Tanzawa Mountains]. M Sc thesis, University of Tokyo, Tokyo: 1-57. [In Japanese]

Mooty J. J., Karns P. D. and Fuller T. K. 1987. Habitat use and seasonal range size of white-tailed deer in northcentral Minnesota. Journal of Wildlife Management 51: 644-648.

Pace C. P. 1958. Herbage production and composition under immature ponderosa pine stands in the Black Hills. Journal of Range Management 11: 238-243.

Peek J. M., Urich D. L. and Mackie R. J. 1976. Moose habitat selection and relationships to forest management in northeastern Minnesota. Wildlife Monographs 48: 1-65.

Shigematsu K. 1996. [Habitat selection of sika deer in Boso Peninsula]. M Sc thesis, University of Tokyo, Tokyo: 1-20+21. [In Japanese] 
Short H. L., Evans W. and Boeker E. L. 1977. The use of natural and modified pinyon pine-juniper woodlands by deer and elk. Journal of Wildlife Management 41: 543-559.

Singer F. J. 1979. Habitat dispersal and wildfire relationships of cervids in Glacier National Park, Montana. Journal of Wildlife Management 43: 437-444.

Takatsuki S. 1983. [Habitat selection by sika deer on Kinkazan Island]. Journal of Mammalogical Society of Japan 9(4): 183-191. [In Japanese with English summary]

Takatsuki S. 1989. Edge effects created by clear-cutting on habitat use by sika deer on Mt. Goyo, northern Honshu, Japan. Ecological Research 4: 287-295.

Takatsuki S. 1990. Changes in forage biomass following logging in a sika deer habitat near Mt. Goyo. Ecological Review 22(1): 1-8.

Takatsuki S. 1991. Food habits of sika deer in Japan with reference to dwarf bamboo in northern Japan. Proceedings of International Symposium on Wildlife Conservation, Tskuba, Yokohama, Japan: 200-204.

Takatsuki S. and Nakano S. 1992. Food habits and pasture use of sika deer at a foothill of Mt. Goyo, northern Japan. Ecological Review 22(3): 129-136.

Thirgood S. J. 1995. The effects of sex, season and habitat availability on patterns of habitat use by fallow deer (Dama dama). Journal of Zoology, London 235: 645-659.

Thirgood S. J. and Staines B. W. 1989. Summer use of young stands of restocked Sitka spruce by red and roe deer. Scottish Forestry 43: 183-191.

Ushizawa R. 1996. [Relations between Sasa hayatae and Sika deer (Cervus nippon) in Mt. Tanzawa]. M Sc thesis, Tokyo University of Agriculture and Technology, Tokyo: 1-50. [In Japanese]

Welch D., Staines B. W., Catt D. C. and Scott D. 1990. Habitat usage by red (Cervus elaphus) and roe (Capreolus capreolus) deer in a Scotish Sitka spruce plantation. Journal of Zoology, London 221: 453-476.

Yeo J. J. and Peek J. M. 1992. Habitat selection by female sitka black-tailed deer in logged forests of southeastern Alaska. Journal of Wildlife Management 56: 253-261.

Recieved 15 Novemeber 1996, accepted 15 April 1997. 